-REVIEW ARTICLE

Volume 15 Issue 22020

DOI: 10.21315/aos2020.15.2.462

ARTICLE INFO

Submitted: 08/07/2020

Accepted: 23/11/2020

Online: 24/12/2020

\section{A Malaysian National Cleft Registry: An Orthodontic Point of View}

\author{
Al Imran Shahrul ${ }^{a}$, Mas Suryalis Ahmad ${ }^{b}$, Nik Mukhriz Mustapha $^{a}$, Aida \\ Nur Ashikin Abd Rahmana* \\ ${ }^{a}$ Centre for Paediatric Dentistry and Orthodontic Studies, Faculty of \\ Dentistry, Universiti Teknologi MARA, 47000 Sungai Buloh Campus, \\ Selangor, Malaysia \\ ${ }^{b}$ Centre of Comprehensive Care Studies, Faculty of Dentistry, Universiti \\ Teknologi MARA, 47000 Sungai Buloh Campus, Selangor, Malaysia \\ ${ }^{\star}$ Corresponding author: aida_nurashikin@uitm.edu.my
}

To cite this article: Shahrul AI, Ahmad MS, Mustapha NM, Abd Rahman ANA (2020). A Malaysian national cleft registry: An orthodontic point of view. Arch Orofac Sci, 15(2): 89-95. https://doi.org/10.21315/aos2020.15.2.462

To link to this article: https://doi.org/10.21315/aos2020.15.2.462

\title{
ABSTRACT
}

Cleft lip and palate (CLP) is one of the most prevalent birth defects. CLP can have a profound physical impact on the child and a psychological impact on both the parents and child. The systemic collection and audit of data on CLP has traditionally been an integral part of comprehensive cleft care. This requires the development of a national cleft registry. This article describes the current orthodontic cleft care, the benefits of a registry and assesses the challenges faced in developing a national cleft registry in Malaysia from an orthodontic point of view.

Keywords: Cleft lip and palate; registry; orthodontic; Malaysia

\section{INTRODUCTION}

Cleft lip and palate (CLP) is one of the most common forms of craniofacial birth defects (World Health Organization, 2003). The aetiology of CLP is not fully understood but it has been proven that there is a strong genetic connection. It is further influenced by environmental and lifestyle factors (Murray, 2002). CLP has a detrimental effect on the facial features and well-being of children in terms of their health, speech, hearing, appearance, dentition and quality of life. Having a team of specialists works on the issue is considered the best option for treatment (Hodgkinson et al., 2005).

The systemic collection and audit of data on CLP has traditionally been an integral part of comprehensive cleft care (Bearn et al., 2001; Shaw et al., 2001). This requires the establishment of a national cleft registry. Reliable and up-to-date data on phenotypes, birth prevalence and outcomes of treatment are essential for the accurate auditing of children born with CLP. Health professionals who manage children with CLP act as sources of information to contribute to the cleft registry. The collection of information may be done on a voluntary basis or under the authority of legislation. The type of reporting used is critical as compulsory reporting will yield a higher amount of data than voluntary outcome reporting (Thong, 2014).

The specialities needed for comprehensive cleft care are plastic surgery, audiology, oral and maxillofacial surgery, orthodontics, otolaryngology/head and neck surgery, 
paediatrics, paediatric dentistry, psychology, speech-language pathology, nursing and genetics. Orthodontists play a crucial role as record keepers on the cleft and craniofacial team. One of the reasons orthodontists have been given the task of record-keeping is because they treat children with CLP most frequently and for the longest duration. There are diverse ranges of orthodonticrelated outcome measures for CLP (Haque et al., 2015a). A simple and accurate outcome measure is essential to the success of a cleft registry.

This article describes the current status of orthodontic cleft care in Malaysia including the benefits and challenges in creating a cleft registry from an orthodontic point of view.

\section{CLEFT CARE IN MALAYSIA}

The prevalence of CLP in Malaysia is approximately one in 941 live birth each year (Oral Health Division, Ministry of Health of Malaysia, 1998). CLP occurs more commonly in females than males, and clefts involving the lip and palate are the most prevalent (Ali Shah et al., 2015). The aetiology of CLP in Malaysia is multifactorial (Ayu et al., 2003; Rahman et al., 2008; Haque et al., 2015b). The Ministry of Health of Malaysia has conducted various health promotion programmes and initiatives to increase women's awareness of the risk of exposure to environmental factors such as tobacco, alcohol, poor nutrition, medicinal drugs and teratogens, and lack of folic acid during pregnancy. Furthermore, there is a strong cultural belief about the cause of CLP among the Malaysian population. However, this cultural belief does not hinder individuals with CLP from seeking treatment from the Malaysian healthcare system (Hussin, 2017).

The Malaysian healthcare system comprises government-managed primary care healthcare centres and hospitals and the stilldeveloping private care, which is primarily situated in physician clinics and hospitals in metropolitan areas. Multidisciplinary CLP treatment is mainly delivered in government hospitals and at some university, military, and private hospitals.

Children with CLP in Malaysia receive the necessary treatment, but there is limited study on the overall outcome of the care being provided (Lee et al., 2004; Zreaqat et al., 2009; 2012; Mohd Ibrahim et al., 2015; Cheong et al., 2016; Zulkipli et al., 2018). The overall outcome of care might vary between regions because some centres have a well-coordinated, multidisciplinary team that meeting on a monthly basis, whereas in some regions, cleft care is poorly centralised and provided by individual clinicians (Mohd Ibrahim et al., 2015).

\section{ORTHODONTIC CLEFT CARE IN MALAYSIA}

Orthodontic care for children with CLP is usually provided in a regional specialist dental clinic. This system requires the orthodontist and patient to travel to the hospital for a joint multidisciplinary clinic. According to the European consensus recommendation (Shaw et al., 2001), orthodontists should treat a minimum of 40 new cases yearly to maintain their experience and specialist skills and to allow audits of their performance. Due to the decentralisation of cleft care in Malaysia, certain orthodontists would not come close to treating 40 new patients annually.

The European consensus recommendation stated that orthodontic care on CLP patients should only be provided by an experienced orthodontist who has undergone special training in cleft care. Currently, there is no restriction about the minimum experience or training a dentist must have to orthodontically treat children with CLP in Malaysia. This lack of regulation will result in considerable variation in the quality of orthodontic treatment offered to children with CLP. 
Due to the lack of official government policy or guidelines, orthodontists use a range of different protocols in their treatments. The general lack of information and policy about treatment protocol and the difference in orthodontists' experience result in a great variation in treatment outcomes. A streamlined protocol should be provided based on the current best evidence. Research is required to assess the treatment outcome and determine the effectiveness of a given protocol. Zreaqat et al. (2009) conducted a retrospective study to establish the treatment outcome based on the dentoalveolar relationship among Malaysian children born with non-syndromic complete unilateral CLP. They concluded that the outcome of treatment is intermediate by utilising the GOSLON Yardstick.

The cost of treatment can vary considerably between centres. The private insurance system in Malaysia does not cover orthodontic treatment costs for cleft care, hence most cleft patients seek care in government-funded centres. The government provides financial support for cleft care in public centres, but only part of the treatment cost is free. This cost will undoubtedly further increase the strain on parents of children with CLP.

\section{THE BENEFITS OF REGISTRIES}

The most obvious function of a registry is to act as a tool for the management of patients who have an ongoing need for medical care (Solomon et al., 1991). A registry particularly useful in cleft care because patients require long-term therapy and a multitude of specialities are involved. Registries can improve orthodontic care for children with CLP and encourage multicentre collaboration in Malaysia by being the apparatus for a community-wide cooperative approach to the handling of cleft patients (Hammond and Stassen, 1999). The establishment of a registry will enable an exchange of knowledge of techniques and the standardisation of protocol based on best evidence, which is currently lacking in Malaysia. The registry also encourages audits and facilitates research by tracking the results of interventions throughout the CLP population. Having a registry will indirectly standardise the record-keeping in Malaysia. A standardised record will facilitate easy comparison between centres nationally or abroad (Shaw et al., 2001).

\section{THE ESTABLISHED REGISTRIES}

The following are good examples of internationally well-established and validated cleft registries that keep records of orthodontic-related outcomes.

The Swedish Quality Registry for CLP started as a collaboration between six Swedish CLP centres in 1999 (Pegelow et al., 2020). The orthodontists in the teams agreed to record the dental occlusions and treatment outcomes in the registry at $5,10,16$, and 19 years of age. In the case of orthognathic surgery, study models for records are taken one-year post-surgery. The outcomes of treatments are assessed by using the Modified Huddart and Bodenham scoring system, 5-year-olds' index and GOSLON Yardstick. Other data recorded related to orthodontics are the cephalometrics value, any orthodontics prior to bone grafting and assessments of bone level in the cleft area.

CleftSiS was built on the foundation laid by the Scottish Association for Cleft Lip and Palate (SCALP). CleftSiS has a record-and-audit protocol based on the recommendations of the Craniofacial Society of Great Britain and Ireland (Clark, 2007). Assessment of the surgical outcomes of primary surgery and secondary alveolar bone grafting, facial profile, skeletal pattern and speech for 5-, 7-, 10-, 15- and 20-yearold patients forms the core of the audit. The clinical data entered into the system are displacement, centrelines discrepancy, overjet, GOSLON Yardstick, 5-year-olds' index, Modified Huddart and Bodenham 
scoring system and any pre-surgical orthopaedics done.

Due to varied outcome measures and the recognised necessity for consensus in this area, the International Consortium for Health Outcome Measurement (ICHOM) created an international, multidisciplinary working group to establish a standard set of outcome measures for the comprehensive assessment of cleft care (Allori et al., 2017). Occlusion is evaluated at 5 and 12 years of age, and again at the end of treatment or at 22 years of age, whichever comes first. ICHOM adopted a clinical examination of overjet based on the GOSLON scale. Patient-reported outcomes are incorporated into the outcome standard. The function of mastication is evaluated by the patientreported CLEFT-Q Eating-and-Drinking scale at 8 and 12 years, and again at the end of treatment or at 22 years of age, whichever comes first.

\section{DISCUSSION}

The establishment of a cleft registry requires meticulous and thorough planning involving comprehensive discussions between experts and open collaboration with a myriad of professional groups and healthcare providers. The development and operation of a registry, therefore, requires a long-term commitment. In many cases, it can take a couple of years to see the full benefits. One challenge in setting up a cleft registry is having a complete data capture. Without legislative authority for data entry, the registry will undoubtedly face difficulty in data collection. The other major problem in the establishment and maintenance of a registry is a cost. The potential benefits of the registry should be evaluated in light of what it will cost to develop and maintain.

In light of the orthodontists' involvement in the registry, standards of assessment and recording should be clear and unambiguous so that orthodontists involved in cleft care will record patient data in a consistent way. There should be a consensus on what outcomes are important. The data and outcome measures should be well-defined and easy to measure.

The most popular and widely accepted outcome index is the GOSLON Yardstick (Mars et al., 1987; Atack et al., 1997). The GOSLON Yardstick provides an outcome index to assess the result of the primary surgery in the early permanent dentition. In Malaysia, providing the professional calibration required for orthodontists to use both indices is a tall order. The requirement to be professionally calibrated in the use of GOSLON Yardstick has been criticised. Consequently, the Modified Huddart and Bodenham scoring system has been suggested as an alternative. It is reliable, quick and easy to perform and its main advantage for orthodontists in Malaysia is that no assessor training is necessary (Gray and Mossey, 2005; Haque et al., 2015a).

ICHOM has elected to use a clinical assessment of the overjet. The ICHOM development group recognised that there is limited evidence for the validity and reliability of this method, but in this case, the group prioritised simplicity and sustainability (Allori et al., 2017). If orthodontists in Malaysia recorded the overjet for every patient at each visit, it would be simpler to compare this data.

Recently, patient-reported outcomes have become a priority in outcome assessments. In an attempt to evaluate patient-reported outcomes, CLEFT-Q has been developed specifically for CLP patients to assess their quality of life (Tsangaris et al., 2017). Malaysia is not a native English-speaking country, therefore, the CLEFT-Q would need to be translated and validated before use.

At the beginning of registry development, it may be a good idea to have fewer variables. Too much data entry should be avoided because in a busy orthodontic practise, data collection is often perceived as extra, unnecessary work. It is important, to keep 
the number of variables to a minimum. Therefore, the initial step in overcoming the challenges is to determine what information should be added to the registry. The cleft teams from various centres should reach a consensus on what outcome measure to be included. Once the majority has agreed, then only is developing a registry worthwhile because the success of a cleft registry is highly dependent on the support from the cleft team members.

Developing a centralised national registry to collect all the data is a huge task due to the number of individuals and centres involved. The first thing that must be done is to centralise the treatment for CLP children to centres with a multidisciplinary team of specialities. Next, an individual centre database must be developed to store all the data from each centre. The database of each centre would then be linked to a national registry. Having individual centres first develop their own database will lessen some of the work of developing a national registry into a smaller, more achievable task.

\section{CONCLUSION}

The systemic collection and analysis of data on children with CLP using a national registry is an essential part of comprehensive cleft care. Orthodontists have an obligation to review the success and shortcomings of treatment. A registry offers significant advantages by providing tools for comparing treatment outcomes between centres. Orthodontists in Malaysia must be aware of the advantages and limitations of each outcome before deciding what should be included in the registry. Careful consideration should be made of what will be included in the registry so as avoid endless data entry, which could deter orthodontists from contributing to it.

\section{REFERENCES}

Ali Shah SY, Abdul Rahman ZA, Mirani SA, Shaikh MI, Khattak MN, Sahito MA (2015). Demographic data on the characterization of oral clefts in Malaysia. Pak Oral Dent F, 35(1): 108-110.

Allori AC, Kelley T, Meara JG, Albert A, Bonanthaya K, Chapman K et al. (2017). A standard set of outcome measures for the comprehensive appraisal of cleft care. Cleft Palate Craniofac F, 54(5): 540-554. https:// doi.org/10.1597/15-292

Atack N, Hathorn I, Mars M, Sandy J (1997). Study models of 5 year old children as predictors of surgical outcome in unilateral cleft lip and palate. Eur $\mathcal{F}$ Orthod, 19(2): 165-170. https://doi.org/10.1093/ ejo/19.2.165

Ayu A, Samsudin AR, Ismail NM, Isa M (2003). Exposure to second-hand smoke and the risk of non-syndromic oral cleft among Malay children in Kelantan. Malays $\mathfrak{f}$ Public Health Med, 3(2): 41-47.

Bearn D, Mildinhall S, Murphy T, Murray JJ, Sell D, Shaw WC et al. (2001). Cleft lip and palate care in the United Kingdom - The Clinical Standards Advisory Group (CSAG) study. Part 4: Outcome comparisons, training, and conclusions. Cleft Palate Craniofac f, 38(1): 38-43. https://doi.org/10.1597/15451569_2001_038_0038_clapci_2.0.co_2

Cheong JP, Soo SS, Manuel AM (2016). Factors contributing to hearing impairment in patients with cleft lip/palate in Malaysia: A prospective study of 346 ears. Int $\mathcal{F}$ Pediatr Otorhinolaryngol, 88: 94-97. https://doi. org/10.1016/j.ijporl.2016.06.045

Clark JD (2007). Managed clinical networks: What are they and how do they work? Dent Update, 34(7): 443-444. https://doi. org/10.12968/denu.2007.34.7.443 
Gray D, Mossey PA (2005). Evaluation of a modified Huddart/Bodenham scoring system for assessment of maxillary arch constriction in unilateral cleft lip and palate subjects. Eur f Orthod, 27(5): 507-511. https://doi.org/10.1093/ejo/cji019

Hammond M, Stassen L (1999). Do you care? A national register for cleft lip and palate patients. $\mathrm{Br} \mathcal{F}$ Orthod, 26(2): 152-157. https://doi.org/10.1093/ortho/26.2.152

Haque S, Alam MK, Arshad AI (2015a). An overview of indices used to measure treatment effectiveness in patients with cleft lip and palate. Malays $\mathcal{F} \mathrm{Med} S \mathrm{Si}, 22(1)$ : 4-11.

Haque S, Alam MK, Basri R (2015b). Gene involvement in cleft lip and palate (CLP) patients. Bangl f Med Sci, 14(1): 113-116. https://doi.org/10.3329/bjms.v14i1.20928

Hodgkinson PD, Brown S, Duncan D, Grant C, McNaughton A, Thomas P, Rye Mattick C (2005). Management of children with cleft lip and palate: A review describing the application of multidisciplinary team working in this condition based upon the experiences of a regional cleft lip and palate centre in the United Kingdom. Fetal Maternal Med Rev, 16: 1-27. https://doi. org/10.1017/S0965539505001452

Hussin I (2017). Cultural beliefs on causes of cleft lip and/or palate and satisfaction of presurgical counselling : A multicenter study. (Master's thesis, Universiti Sains Malaysia). Retrieved from http://eprints. usm.my/44981/

Lee CT, Grayson BH, Cutting CB, Brecht LE, Lin WY (2004). Prepubertal midface growth in unilateral cleft lip and palate following alveolar molding and gingivoperiosteoplasty. Cleft Palate Craniofac F, 41(4): 375-380. https://doi. org/10.1597/03-037.1
Mars M, Plint DA, Houston WJ, Bergland O, Semb G (1987). The Goslon Yardstick: A new system of assessing dental arch relationships in children with unilateral clefts of the lip and palate. Cleft Palate $\mathcal{F}$, 24(4): 314-322.

Mohd Ibrahim H, Mohamed Yusoff FH, Ahmad K, Van Dort S (2015). An exploratory study on speech and hearing outcomes in children with cleft lip and palate. Med $\mathcal{F}$ Malays, 70(6): 321-325.

Murray JC (2002). Gene/environment causes of cleft lip and/or palate. Clin Genet, 61(4): 248-256. https://doi.org/10.1034/j.13990004.2002.610402.x

Oral Health Division, Ministry of Health of Malaysia (1998). National Oral Health Survey of Schoolchildren 1997 (NOHSS '97). Putrajaya: Oral Health Division, Ministry of Health of Malaysia.

Pegelow M, Klintö K, Stålhand G, Lemberger M, Vesterbacka M, Rizell S et al. (2020). Validation of reported dentoalveolar relationships in the Swedish quality registry for cleft lip and palate. Eur $\mathcal{F}$ Orthod, 42(1): 30-35. https://doi.org/10.1093/ejo/cjz069

Rahman RA, Ahmad A, Rahman ZA, Mokhtar KI, Lah NA, Zilfalil BA, Samsudin AR (2008). Transforming growth factor- $\alpha$ and nonsyndromic cleft lip with or without palate or cleft palate only in Kelantan, Malaysia. Cleft Palate Craniofac $\mathcal{F}, 45(6)$ : 583-586. https://doi.org/10.1597/07-020.1

Shaw WC, Semb G, Nelson P, Brattström V, Mølsted K, Prahl-Andersen B et al. (2001). The Eurocleft Project 19962000: Overview. F Craniomaxillofac Surg, 29(3): 131-140. https://doi.org/10.1054/ jcms.2001.0217

Solomon DJ, Henry RC, Hogan JG, Van Amburg GH, Taylor J (1991). Evaluation and implementation of public health registries. Public Health Rep, 106(2): 142-150. 
Thong MK (2014). Birth defects registries in the genomics era: Challenges and opportunities for developing countries. Front Pediatr, 2: 60. https://doi.org/10.3389/ fped.2014.00060

Tsangaris E, Riff KWYW, Goodacre T, Forrest CR, Dreise $M$, Sykes J et al. (2017). Establishing content validity of the CLEFT-Q: A new patient-reported outcome instrument for CLEFT lip/ palate. Plast Reconstr Surg Glob Open, 5(4): e1305. https://doi.org/10.1097/ GOX.0000000000001305

World Health Organization (2003). Global Registry and Database on Craniofacial Anomalies. Report of a WHO Registry Meeting on Craniofacial Anomalies. Geneva: World Health Organization.
Zreaqat M, Hassan R, Halim AS (2009). Dentoalveolar relationships of Malay children with unilateral cleft lip and palate. Cleft Palate Craniofac F, 46(3): 326-330. https://doi.org/10.1597/07-210.1

Zreaqat M, Hassan R, Halim AS (2012). Facial dimensions of Malay children with repaired unilateral cleft lip and palate: A three dimensional analysis. Int $\mathcal{f}$ Oral Maxillofac Surg, 41(6): 783-788. https:// doi.org/10.1016/j.ijom.2012.02.003

Zulkipli AS, Alam MK, Patel ES, Haque S (2018). A perceptual evaluation of resonance disorders in children with repaired unilateral cleft lip and palate in Hospital Universiti Sains Malaysia. Bangl f Med Sci, 17(2): 282-289. https://doi. org/10.3329/bjms.v17i2.35885 